\title{
"Genetics" and how we made it
}

\author{
Steven Rose, Professor of Biology at the Open University, looks \\ at the origins and purpose of the OU's new genetics course
}

INCE the beginning of this month
some 900 Open University students have been settling down for their standard 12 hours study a fortnight to follow a new second level Genetics Course-a set of 16 sequential study Units ranging in context from classical genetics by way of molecular and cytological genetics to population and human genetics, each with an accompanying TV and radio programme and a series of "home experiments". What makes the Genetics Course different from all the rest of the OU science teaching, however, is that it is the result of almost 3 years of collaboration between the Biology Department of the OU and the Department of Genetics at Birmingham, the Unit of Genetics at Hull, the School of Biology at Sussex and a member of the biology staff at the University of York. Teaching staff from the four collaborating universities were released from most of their other teaching duties in order to work on the production of this Course - a participation made possible by a grant from the Nuffield Foundation, which has an interest both in promoting inter-university teaching projects and in the development of the type of structured teaching that the OU has pioneered at University level. But the involvement was not just that of individuals, for each participant had the support of his department and access to its own particular area of genetic and teaching expertise. The result has been a novel Course that can be used both by the $\mathrm{OU}$ and in many other teaching institutions.

There were several reasons for choosing genetics for this experiment. The modern synthesis of genetics underlies most areas of biology. It is a subject that, throughout its history, and to the present day, has been interwoven with social and philosophical controversy concerning its interpretation and implications. It is very well suited for a problem-oriented, studentactive teaching approach. And finally, a prosaic but important point is that not even all universities, and certainly rather few polytechnics and colleges, have biology schools large enough to be able to teach Genetics across the full range, from the molecular to the population and human levels. Hence the brief of the Joint Universities Genetics Course Team has been to prepare a Course that will eventually be able to be used in whole or in part by a very wide range of institutions even when they do not have a full range of genetic skills represented amongst their teaching staff.

Working as an inter-university team has had both its pleasures and its perils. We came into the venture with differing views, based on our differing experiences, not merely on what should be taught but on how it should be taught. University teachers tend to be individualists, but, meeting practically monthly since 1973, together with the BBC staff, educational technologists, technicians and researchers who comprise the full Course Team, has welded us into a collective teaching group. In such a team, every assertion about what should be included and how it should be approached has to meet the challenge and critical assessment of our colleagues. We have been able to seek the advice of expert assessors outside the team to comment on various sections of the Course during its development and to call on a panel of students to assess the drafts of the Units for their success as teaching documents, so as to point to areas of potential obscurity or theoretical or factual overload. It has been particularly instructive and we believe useful to have had, for instance, biometricians confronted with developmental geneticists and being forced to convince each other-and the rest of us- of the case for including their respective approaches in a Course in which every minute of the students' time is precious and academic pretentiousness or hobbyhorses cannot intrude. One result, incidentally, has been a considerable rethinking of the amount of mathematics that is essential to an understanding of biometry at this level and a series of experiments in ways of presenting it which we have been able to test with a number of volunteer students.

\section{The Course itself}

The Course itself, seen as a linear sequence (although each of its Units may be used separately) begins by asking: What is genetics? What sorts of questions do geneticists ask and how do they obtain the answers? Not surprisingly it goes back to Mendel, and includes a reprint of a translation of his original (1865) paper at this point. There follow four Units on chromosomes and genes; recombination; linkage and maps; and chromosome organisation and changes. The next three Units cover molecular genetics, cytoplasmic inheritance and developmental genetics and there are five Units on the analysis of populations, biometry, plant

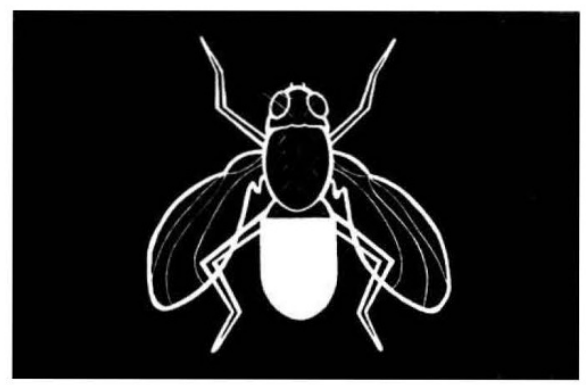

and animal breeding and evolutionary and ecological genetics. The final two Units focus on human genetics, and confront some of the major currently controversial issues in human genetics (for instance the question of whether the biometrical approach has anything to contribute to the analysis of group differences in IQ score, the XYY programme and the prospect of genetic engineering). The main teaching sequence is accompanied by a parallel Unit which sets present-day genetic theories into the context of their history and social relations (not forgetting past controversies like that around eugenics and social Darwinism). There is also a specially prepared statistics Unit. All the texts are designed to be self-instructional, with opportunities for the students to assess their own progress by tackling problems en route through the Units (OU students will also have a series of programmed tutorials through the year).

Integral to the teaching material are the video and audio tapes, which will be transmitted fortnightly by the $\mathrm{BBC}$ over the year, beginning this month. The TV includes both studio animations and experimental demonstrations and also film material involving many leading geneticists, both in this country and abroad, in their own labs or in the field. The radio has a varied role, from radio-vision (for example of finestructure genetic mapping and the derivation of biometric equations) through to historical programmes on the development of phage genetics and the Lysenko episode. Among those taking part in radio or TV programmes (apart from members of the Course Team itself) are Bradshaw, Cain, Crick, Delbrück, Edgar, Lewontin, Levins, Luria, Sager, Sonneborn, Stent, Stern, Suzuki and Watson.

Finally, for OU students there is a "package" of experiments to be done at home which include genetic studies on tomato seedlings, on microorganisms and Drosophila, as well as a set of observations to be made on humans which will be sent back to be analysed centrally for their genetical implications.

For OU students taking the Course this vear. it will be just one component of their degree programme. But at the 
same time they will be participating in the final stages of a substantial experiment. Throughout the year we will be monitoring their progress, and that of students at some conventional universities and colleges who are also using the Course or parts of it. For only this will tell us how close we are to our ultimate objective $-a$ first rate and comprehensive second level genetics teaching Course which can be widely used in Britain and abroad.

\section{Environmental protection under state socialism}

In the Soviet Union environmental issues have surfaced in recent years as just one consequence of the country's rapid development. The problems seem as intractable there as anywhere else. Vera Rich reports.

ECOLOGICAL problems seem to be as much a concern of the Soviet Union as they are of other industrialised countries. The prospectus for the Five-Year Plan lays considerable stress upon conservation and environmental protection, and the science and technology section includes among its major aims: "to study the scientific principles of the use and conservation of soils, mineral resources, the plant and animal worlds, the air, and water basins. To expand complex investigations of the world's oceans. To effect the further development of methods of forecasting the weather and natural disasters".

Commenting on this programme in the English-language Moscow News (No. 1, 1976), Academician Inokentii Gerasimov implies that the problem of conservation, although a real one, arising from rapid urbanisation and industrialisation, is nevertheless qualitatively different from that in capitalist countries: in the Soviet Union, he argues, "there are no social reasons for for the irrational utilisation of natural wealth. Environmental protection under socialism, with its planned economy and no privately owned natural resources, becomes an important task of the state. Hence, environmental protection in our country is part of the current and long-term economic plans".

Taken at its face value, Gerasimov's comment would imply that, in the Soviet Union, any ecological hazard would be of a short-term nature only: the result of a temporary imbalance between one part of the Plan and another. Such short-term imbalances do occur, and at a fairly low level of the administrative hierarchy may become the subject of criticism in the media. Last November, for example. Minsk Radio noted that reafforestation (to replace planned felling) in Byelorussia was falling behind schedule, while in the Brest, Minsk and Grodno Oblasts, excessive felling had taken place and the authorities concerned had failed to take the required "essential measures" against fire and timberpoaching. "Anti-social elements"--fishstealers, litter-droppers, and others who have not yet learned the norms of behaviour proper to a socialist society -present another possible environmental threat. They too are the subject of exhortation in the media, particularly at the local level; on occasion, the state-sponsored Society of the Friends of Nature has been called upon to organise vigilantes to deal with a particular outbreak of "hooliganism".

These, one might conclude from Gerasimov, are the main dangers to the Soviet environment-fairly local and minor disturbances, far down the administrative and social ladder. In fact, the problem is somewhat more complex. The Soviet authorities have in recent years become increasingly aware that their natural resources, though vast, do not constitute the infinity promised to Peter the Great by his geographers. At the Twenty-Fourth Party Congress in 1971, Mr Brezhnev stressed this new approach: "As we take steps to accelerate scientific and technological progress," he said, "we must ensure that this is combined with the rational use of natural resources and should not cause dangerous pollution of air or water, nor exhaust the soil",

This marks a fairly new approach. The early years of the Soviet Union were marked by rapid industrialisation. On posters and cartoons, the smoking factory chimney became the standard symbol for progress. In accordance with Lenin's equation (Communism $=$ Socialism + Electrification), rivers were dammed and spillways built with little, if any concern for the ecological consequences. The writings of Marx dwell mainly on the urban proletariat and barely touch on conservation; and from Lenin's work isolated quotations can he extricated to serve as slogans. Concern was directed more towards utilising than conserving natural resources; of the major theoreticians, only Engels showed concern with the long-term outcome of remodelling the environment. For many reasons, per- haps ideological as well as practical, the relevant passages seemed to make little impression on the planners. To turn rivers aside from their courses, to plant orchards where there once were deserts, to carpet the barren steppe with horizon-to-horizon grain-fields-such achievements, as well as bringing immediate economic benefits, would demonstrate at home and abroad the intrinsic superiority of the Soviet system of planning.

In the 1920s, of course, in spite of industrial expansion during the last decades of Tsarism, the vast majority of the Soviet Union was still in the state of a country emerging from fcudalism, and a system of tied serfdom remained within living memory. Thus, after some elementary laws were passed-the nationalisation of land, the prohibition of fish poaching, the establishment of certain national parks and health resorts-little attention was given to ecological problems: the drive to take the country into the twentieth century outweighed all other considerations. Only two major pieces of conservation legislation were passed under Stalin. These dealt with the establishment of "shelter belts" of trees to prevent erosion (1948) and the control of air pollution (1949), and the first remained something of a dead letter.

Only during the late 1950s, under Khrushchev's policy of opening up undeveloped areas, were a large number of laws passed on conservation and the environment, reflecting a growing awareness of the need for a coherent policy in this field. In many cases, the laws passed at that time set extremely high standards, as though they were intended as "socialist ideals" rather than practical policies: in certain cases virtually the same law was promulgated several times, suggesting considerable difficulties in implementation. Nevertheless, the laws were published in the press and became common knowledge. In the atmosphere of "the thaw", concerned individuals began to voice protests against the most flagrant infringements either officially, or, later, through the samizdat literature. Furthermore, the growing international concern with conservation impelled the Soviet authorities, if only for prestige reasons, to show that the homeland of socialism was not lagging behind in its concern about a universally pressing problem. It is now clear that many of the "developers" were, by present standards, carried too far by their zeal. Many recent Soviet "achievements" in 